\title{
Reasons for and patterns relating to the extraction of permanent teeth in a subset of the Saudi population
}

This article was published in the following Dove Press journal:

Clinical, Cosmetic and Investigational Dentistry

30 July 2013

Number of times this article has been viewed

\author{
Khalil Alesia' \\ Hesham S Khalil ${ }^{2}$ \\ 'Department of Prosthetic Dental \\ Sciences, ${ }^{2}$ Department of Oral and \\ Maxillofacial Surgery, College of \\ Dentistry, King Saud University, \\ Saudi Arabia
}

Background: The purpose of this study was to investigate the reasons for and patterns of extraction of permanent teeth in a subset of the Saudi population.

Methods: During a 3-month period, dentists were asked to record, using a specially designed survey form, the reasons for every extraction of a permanent tooth. The reasons for tooth extraction were assigned to different causes, ie, dental caries, periodontal disease, eruption problems, trauma, orthodontics, failed root canal treatment, and others. The data requested for each extraction were: patient age, gender, nationality, and type of tooth removed and the reason for its extraction.

Results: The highest percentage of extractions was observed in young females aged 10-30 years. Presence of caries was observed to be the main reason for extraction $(50.2 \%)$ followed by orthodontic problems $(18.2 \%)$, eruption problems $(17.5 \%)$, and periodontal problems $(8.2 \%)$. The most frequently extracted posterior teeth were the third mandibular molar $(19.4 \%)$, the third maxillary molar (16.4\%), the first maxillary premolar $(13.2 \%)$, and the first mandibular molar (10.9\%).

Conclusion: Dental caries was found to be the most common reason for extraction of teeth Molar teeth were found to be the most frequently extracted, with an increased number of extracted first premolars as a result of orthodontic treatment. The highest percentage of extractions was observed in young females aged 10-30 years.

Keywords: extraction, Saudi, teeth, reasons, permanent

\section{Introduction}

Loss of teeth continues to be a major public health problem worldwide. Many reasons have been given to account for such extractions, including the presence of caries, periodontal disease, orthodontic treatment, trauma, and prosthetic procedures ${ }^{1-11}$ In many studies, caries was reported to be the most frequent reason for tooth extraction, followed by periodontal disease. ${ }^{12}$ However, due to advances in preventive measures, periodontal disease became the main reason for extraction only in males aged 46-65 years. Anterior teeth, especially in the mandible, represent the highest percentage of extractions resulting from periodontal involvement. ${ }^{12} \mathrm{~A}$ variety of reasons has been given in the literature to account for the considerable difference in maxillary tooth loss observed between males and females. While maxillary premolars and molars in males were mainly extracted as a result of periodontal disease, as was the case for caries, the presence of caries was the main reason for loss of all maxillary teeth in females. ${ }^{13}$

Great variation exists in the frequency and causes of tooth extraction in different countries. In Singapore, a survey of the reasons for tooth extraction showed that the
Department of Oral and Maxillofacia Surgery, College of Dentistry, King Saud University, Saudi Arabia Tel +96 6I I467 74l4

Email hkhalil@ksu.edu.sa 
percentage of teeth extracted for periodontal reasons and caries was about the same. In patients above 40 years, an average of $76 \%$ of teeth were lost for periodontal reasons, while an average of $26.7 \%$ of teeth were lost for periodontal reasons in patients under 40 years. ${ }^{14}$ In Brazil, $70 \%$ of tooth extraction was found to be due to caries, while extraction because of periodontal disease accounted for only $15 \% .{ }^{1}$ Both caries and periodontal disease were shown to be the main reasons for tooth extraction in the north of Afghanistan. ${ }^{15}$ Investigation of the reasons for extraction at four dental practices in southern Wales showed that caries was the main reason for tooth extraction $(59 \%)$ in patients attending for routine dental treatment; and periodontal disease was the second most common reason $(29 \%))^{2}$ A survey carried out in Jordan suggested that caries and its consequences are responsible for most tooth loss in patients under 40 years of age, while extraction because of periodontal problems increases with age. ${ }^{16}$ Another study in Jordan showed that tooth extraction due to dental caries was distributed equally among males and females. Those who reported irregular tooth brushing and made fewer dental visits had significantly more third molar teeth extracted due to caries and periodontal disease compared with those who reported regular tooth brushing and making regular dental visits. ${ }^{17}$ In Scotland, the overall number of extractions has decreased over the last 15 years, and premolars were the teeth most commonly removed below the age of 21 years. This observation may be due to an increase in orthodontic extractions in this age group or to a decline in extractions due to caries. However, when extractions in the population as a whole are considered, caries and its sequelae remain the principal reason for loss of all tooth types except for the lower incisors, which are generally extracted for periodontal reasons. ${ }^{18}$

Molar teeth are the most commonly extracted teeth in Tanzania, ${ }^{9}$ and the third molar is the tooth most often extracted in western regions of Germany. ${ }^{4}$ The presence of pain was shown to be the main reason for extraction, while periodontal disease was the most frequent cause of tooth extraction for people over 40 years of age. ${ }^{4}$ In Hong Kong, caries was reported to be the main reason given by dentists for tooth extractions in all age groups. ${ }^{6}$ Formation of caries is also the most important cause of tooth extraction, and is predicted to remain the most important challenge for the Hungarian dental service during the upcoming decades. ${ }^{7}$ An assessment of tooth loss data from a range of countries is essential for evaluating the adequacy of dental care, as well as being important for the establishment of oral health programs and understanding the various factors which cause
Table I Numbers and percentages of extracted teeth in patients according to age group

\begin{tabular}{llll}
\hline $\begin{array}{l}\text { Age group } \\
\text { (years) }\end{array}$ & $\begin{array}{l}\text { Numbers } \\
\text { of extracted } \\
\text { teeth in males }\end{array}$ & $\begin{array}{l}\text { Numbers } \\
\text { of extracted } \\
\text { teeth in females }\end{array}$ & Total \\
\hline $10-20$ & 154 & 295 & 449 \\
& $(22.3 \%)$ & $(34.2 \%)$ & $(28.9 \%)$ \\
$21-30$ & 160 & 290 & 450 \\
& $(23.2 \%)$ & $(33.6 \%)$ & $(29 \%)$ \\
$31-40$ & 115 & 130 & 245 \\
& $(16.6 \%)$ & $(15.1 \%)$ & $(15.8 \%)$ \\
$41-50$ & 108 & 84 & 192 \\
& $(15.6 \%)$ & $(9.73 \%)$ & $(12.4 \%)$ \\
$51-60$ & 101 & 55 & 156 \\
& $(14.6 \%)$ & $(6.37 \%)$ & $(10 \%)$ \\
$61-70$ & 33 & 8 & 41 \\
& $(4.78 \%)$ & $(0.93 \%)$ & $(2.64 \%)$ \\
$>70$ & 20 & 1 & 21 \\
& $(2.89 \%)$ & $(0.12 \%)$ & $(1.35 \%)$ \\
\hline
\end{tabular}

Notes: $\chi^{2}=114.111$, degrees of freedom $=6, P<0.0001$.

tooth loss. The studies described here aim to investigate the reasons for and patterns of permanent teeth extraction in the Saudi population.

\section{Materials and methods}

The present study involved two major centers for dental treatment in Riyadh city, the capital of Saudi Arabia, including the College of Dentistry, King Saud University, and Riyadh Dental Center, Ministry of Health. The selection of these two centers was based on their location, representing the center and periphery of Riyadh city, and the numbers of patients who could be recruited into the study during a short period

Table 2 Numbers of extracted teeth in males and females according to reasons for extraction

\begin{tabular}{llll}
\hline Reasons for extraction & Male & Female & Total \\
\hline Caries & 370 & 410 & 780 \\
& $(53.5 \%)$ & $(47.5 \%)$ & $(50.2 \%)$ \\
Failed root canal treatment & 8 & 8 & 16 \\
& $(1.16 \%)$ & $(0.93 \%)$ & $(1.03 \%)$ \\
Periodontal problems & 64 & 64 & 128 \\
& $(9.26 \%)$ & $(7.42 \%)$ & $(8.24 \%)$ \\
Trauma & 2 & 0 & 2 \\
& $(0.29 \%)$ & $(0 \%)$ & $(0.13 \%)$ \\
Eruption problems & 110 & 163 & 273 \\
& $(15.9 \%)$ & $(18.9 \%)$ & $(17.6 \%)$ \\
Orthodontic problems & 102 & 181 & 283 \\
& $(14.8 \%)$ & $(21 \%)$ & $(18.2 \%)$ \\
Preprosthetic & 34 & 36 & 70 \\
Others & $(4.92 \%)$ & $(4.17 \%)$ & $(4.5 \%)$ \\
& 1 & 1 & 2 \\
\hline
\end{tabular}

Notes: $\chi^{2}=19.577$, degrees of freedom $=1, P<0.0001$. 
Table 3 Numbers of extractions according to tooth type in the maxilla and mandible

\begin{tabular}{|c|c|c|c|c|c|c|c|c|c|}
\hline \multirow[t]{2}{*}{ Tooth } & \multirow[t]{2}{*}{ Jaw } & \multicolumn{7}{|c|}{ Age group, years } & \multirow[t]{2}{*}{ Total } \\
\hline & & $10-20$ & $21-30$ & $31-40$ & $41-50$ & $5 I-60$ & $61-70$ & $>70$ & \\
\hline \multirow[t]{2}{*}{ Third molar } & Maxillary & 47 & 99 & 47 & 23 & 13 & 1 & 2 & $232(14.93 \%)$ \\
\hline & Mandibular & 65 & 135 & 43 & 19 & 9 & 3 & 0 & $274(17.63 \%)$ \\
\hline \multirow[t]{2}{*}{ Second molar } & Maxillary & 4 & 22 & 19 & 21 & 11 & 4 & 2 & $83(5.34 \%)$ \\
\hline & Mandibular & 4 & 20 & 14 & 10 & 9 & 4 & I & $62(3.99 \%)$ \\
\hline \multirow[t]{2}{*}{ First molar } & Maxillary & 27 & 29 & 32 & 21 & 10 & 3 & 4 & $126(8.10 \%)$ \\
\hline & Mandibular & 54 & 36 & 20 & 27 & 12 & 4 & I & 154 (9.91\%) \\
\hline \multirow[t]{2}{*}{ Second premolar } & Maxillary & 15 & 28 & 13 & II & II & 5 & 2 & 85 (5.47\%) \\
\hline & Mandibular & 42 & 8 & 12 & 10 & 17 & 1 & 0 & $90(5.79 \%)$ \\
\hline \multirow[t]{2}{*}{ First premolar } & Maxillary & 109 & 37 & 10 & 13 & 10 & 4 & 4 & 187 (I2.03\%) \\
\hline & Mandibular & 68 & 21 & 3 & 7 & 15 & 3 & 0 & II (7.52\%) \\
\hline \multirow[t]{2}{*}{ Canine } & Maxillary & 4 & 3 & 6 & 12 & 3 & 3 & 2 & $33(2.12 \%)$ \\
\hline & Mandibular & I & 2 & 3 & 3 & 11 & 2 & 3 & 25 (1.60\%) \\
\hline \multirow[t]{2}{*}{ Lateral incisor } & Maxillary & 3 & 1 & 6 & 0 & 2 & 0 & 0 & $12(0.77 \%)$ \\
\hline & Mandibular & 0 & 0 & 6 & 3 & 14 & 1 & 0 & 24 (I.54\%) \\
\hline \multirow[t]{2}{*}{ Central incisor } & Maxillary & 6 & 7 & 6 & 5 & 1 & 2 & 0 & 27 (1.73\%) \\
\hline & Mandibular & 0 & 2 & 5 & 7 & 8 & I & 0 & 23 (1.48\%) \\
\hline
\end{tabular}

Notes: Maxillary, $\chi^{2}=220.621$, degrees of freedom $=42, P<0.0001$; mandibular, $X^{2}=348.727$, degrees of freedom $=42, P<0.001$.

of time. The study design and survey were approved by the College of Dentistry Research Center. Dentists recruited for the study were randomly selected from the workers list at the two centers. The dentists selected were interviewed and the objectives of the study and survey were discussed with them. Participating dentists were asked to record the reasons for permanent teeth extraction at their clinics on a specially designed survey form that included patient's details such as age, gender, and tooth type. All Saudi patients who needed dental extraction were included in the study. The survey form consisted of a single page and was designed to be as simple as possible. The reasons for tooth extraction were assigned as: dental caries, periodontal disease, eruption problems, trauma, orthodontics, failed root canal treatment, and miscellaneous. Other data requested for each extraction included patient age, gender, nationality, type of tooth removed, and the reason for extraction. Data were collected over a 3-month period and analyzed descriptively using Statistical Package for Social Sciences version 17 software (SPSS Inc, Chicago, IL, USA), and a comparison of different factors was done using the Chi-square test.

\section{Results}

The survey questionnaire data concerning the reasons for and patterns of tooth extractions in 1554 Saudi patients (691 males and 863 females) were analyzed over a 3-month period at two major dental treatment centers in Riyadh city. The numbers and percentages of teeth extracted during this period are shown by age group in Table 1 . The number of teeth extracted was different for the different age groups, and dental caries accounted for the majority (50.2\%) of extractions in all age groups. Orthodontic considerations were found to be the second most common reason for extraction (18.2\%) followed by periodontal disease, which accounted for $8.2 \%$ of all extractions (Table 2). The highest percentage of extractions was observed in young females aged $10-30$ years.

The most commonly extracted tooth type in all age groups was the molars $(60 \%)$, followed by premolars $(30.8 \%)$ and anterior teeth $(9.2 \%$, Table 3$)$. The most frequently extracted posterior tooth was the third mandibular molar (19.4\%), the third maxillary molar (16.4\%), the first maxillary premolar (13.2\%) and the first mandibular molar (10.9\%). The tooth type showing the lowest number of extractions was the maxillary lateral incisor $(0.7 \%$, Figure 1$)$. Premolars were mainly extracted because of orthodontic problems (47\%), while molar teeth were extracted mainly because of dental caries $(56 \%)$, followed by eruption problems, such as impaction (27\%), (Table 4).

\section{Discussion}

Tooth loss is the dental equivalent of mortality. The end result of oral disease can reflect both the patient's own attitude to dental hygiene and the availability and accessibility of oral health care. Little is known about the reasons for and pattern of tooth extraction in the Saudi population. It has been shown in a previous study that $62 \%$ of extractions of permanent and primary teeth in Saudi Arabia were due to caries, with periodontal disease being the main reason for extraction in patients over 40 years of age. ${ }^{19}$ In the current study, the percentage of teeth extracted due to caries was 


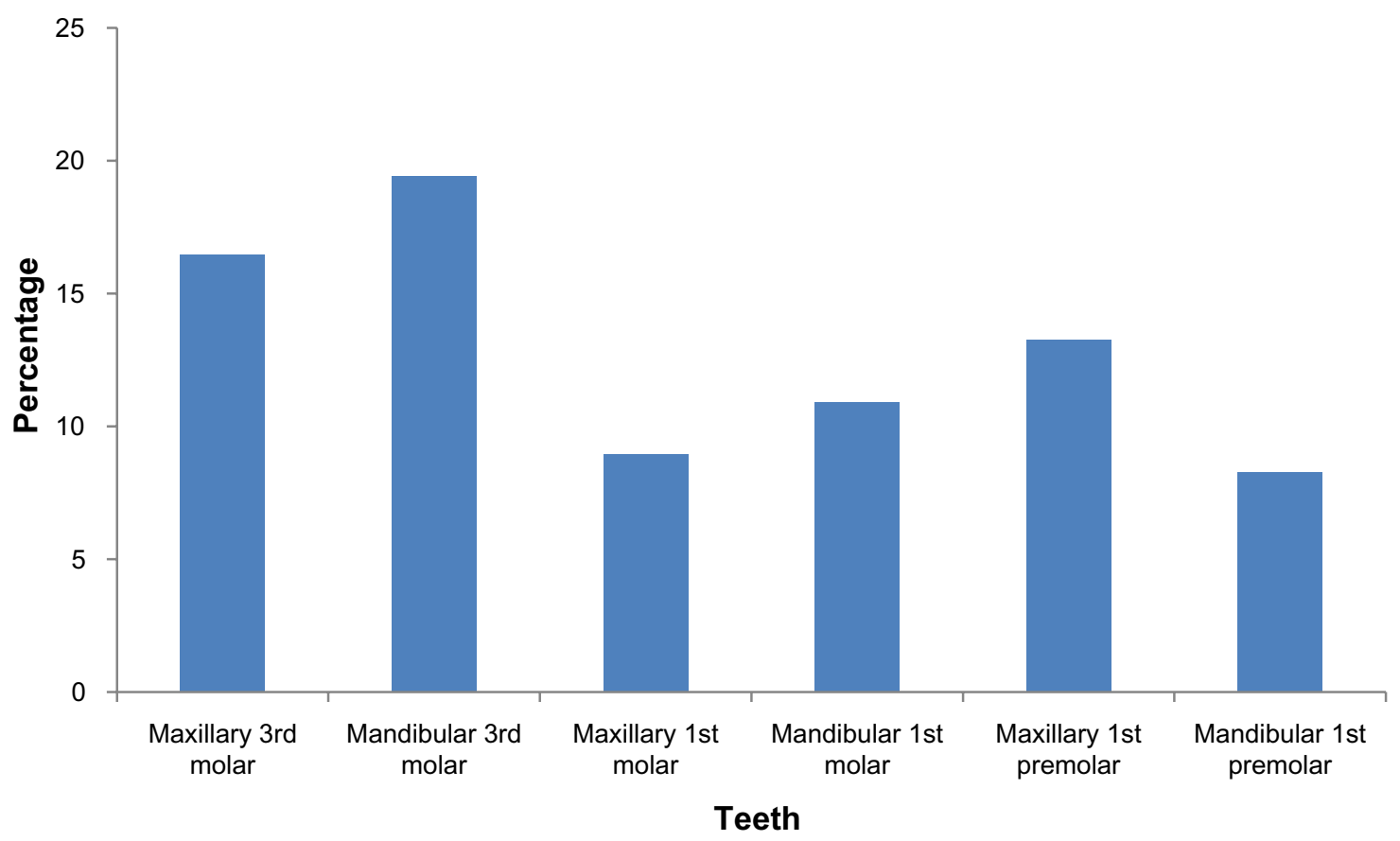

Figure I Percentages of most commonly extracted posterior teeth.

$50.2 \%$, with more extractions because of caries in females compared with males. The higher percentage of extractions in females may be due to their commitment to managing dental problems compared with males. The percentage of extraction of teeth due to caries in the literature ranges from $20 \%$ to $60 \%{ }^{13,14,17,18,20-22}$ A recent statistical analysis by the Central Department of Statistics and Information of Saudi Arabia showed that more than $75 \%$ of the Saudi population is aged $0-39$ years and that this young generation has benefited from preventive programs implemented by many dental schools and governmental hospitals. ${ }^{23}$ Although periodontal disease has been shown to be the second major reason for tooth extraction in many studies, ${ }^{14,18,20,24}$ the present study shows that extraction for orthodontic problems was the second major reason for tooth extraction among
Saudis (Figure 2). These findings are similar to those of a study conducted in Jordan, and could be related to the increasing interest in esthetic considerations in the general population. ${ }^{25}$ Many studies have shown that the molars are the most commonly extracted teeth. ${ }^{12,19}$ Wahab, for example, showed that of all teeth extracted due to caries, molars were the most frequently extracted $(56.9 \%){ }^{25}$ In the present study, extraction of molar teeth accounted for $60 \%$ of all extractions, followed by extractions of premolars and anterior teeth. Extraction of these molars was mainly due to the presence of caries and eruption problems, followed by periodontal disease. Extraction of anterior teeth was mainly due to caries and periodontal disease, followed by preprosthetic considerations, and mandibular anterior teeth were extracted more frequently than maxillary teeth. The most

Table 4 Numbers and percentages of extractions according to reasons for extraction and tooth type

\begin{tabular}{|c|c|c|c|c|c|c|c|c|c|c|}
\hline \multirow[t]{2}{*}{ Tooth type } & \multirow[t]{2}{*}{ Jaw } & \multicolumn{8}{|c|}{ Reason of extraction } & \multirow[t]{2}{*}{ Total } \\
\hline & & Caries & Failed RCT & Perio & Trauma & Eruption & Ortho & Preprosthetic & Others & \\
\hline \multirow[t]{2}{*}{ Molar } & Maxillary & 256 & 2 & 32 & 0 & 99 & 27 & 18 & I & 435 (27.99\%) \\
\hline & Mandibular & 274 & 7 & 24 & 0 & 156 & 28 & 6 & I & $496(31.92 \%)$ \\
\hline \multirow[t]{2}{*}{ Premolar } & Maxillary & 123 & 5 & 12 & 0 & 5 & 129 & 7 & 0 & $28 \mathrm{I}(18.08 \%)$ \\
\hline & Mandibular & 73 & I & 7 & 0 & 7 & 98 & 12 & 0 & $198(12.74 \%)$ \\
\hline \multirow[t]{2}{*}{ Canine } & Maxillary & 17 & 0 & 6 & 0 & 5 & I & 4 & 0 & $33(2.12 \%)$ \\
\hline & Mandibular & 11 & 0 & 8 & I & 1 & 0 & 4 & 0 & $25(1.60 \%)$ \\
\hline \multirow[t]{2}{*}{ Incisor } & Maxillary & 14 & I & 15 & I & 0 & 0 & 5 & 0 & 36 (2.3।\%) \\
\hline & Mandibular & 12 & 0 & 24 & 0 & 0 & 0 & 14 & 0 & $50(3.21 \%)$ \\
\hline
\end{tabular}

Abbreviations: RCT, root canal treatment; Perio, periodontal; Ortho, orthodontal. 


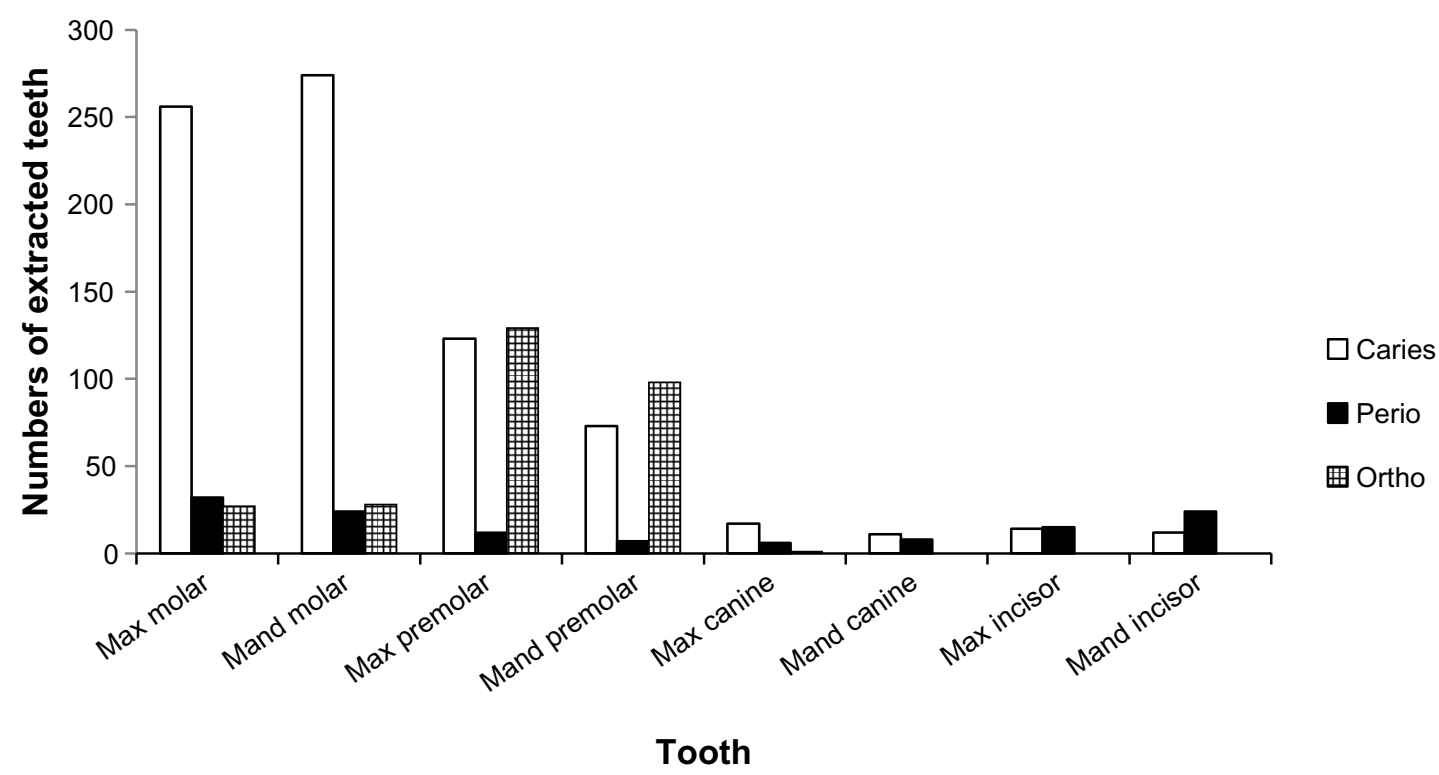

Figure 2 Numbers of extracted upper and lower teeth due to caries, periodontal disease, and orthodontic reasons. Abbreviations: Max, maxillary; mand, mandibular; Perio, periodontal; Ortho, orthodontic.

frequently extracted tooth was the third mandibular molar followed by the third maxillary molar and first premolar. The majority of extractions of third molars occurred in the age group 21-30 years (48.2\%), while most of the extracted first premolars (58\%) occurred in the age group 10-20 years. Such data for tooth loss in developing countries provides information related to dental health status in young people and may serve as baseline data for evaluation of future dental health programs. Moreover, the pattern of tooth loss has been generally regarded as one of the most important measures needed for assessing the standards, availability, and utilization of both curative and preventive dental care in a given population. Compared with a previous study conducted by Farsi in $1992^{19}$ reporting the reasons of extraction in Saudi Arabia, the reasons for extraction may have changed in this country over recent years. Although caries remains the leading cause of tooth extraction, there has been an increase in the extractions currently carried out for orthodontic reasons which may reflect patient concerns.

\section{Conclusion}

Within the limitations of the present study, the results indicate that caries and orthodontic considerations are the main reasons for tooth extraction in Saudi patients. When compared with a previous study in Saudi Arabia, the results of the current study show that there has been a reduction in extractions due to caries, which may be due to implementation of various preventive programs. Molar teeth are the most frequently extracted, with an increased number of first premolars extracted resulting from orthodontic treatment. In conclusion, further preventive programs need to be implemented in order to decrease extraction of teeth for the common reasons discussed here.

\section{Acknowledgment}

The authors would like to thank Nasser Meflhi for his guidance with statistical analysis of the data. This research was funded by the College of Dentistry Research Center, King Saud University (F1162).

\section{Disclosure}

The author reports no conflicts of interest in this work.

\section{References}

1. Caldas AF Jr. Reasons for tooth extraction in a Brazilian population. Int Dent J. 2000;50(5):267-273.

2. Richards W, Ameen J, Coll AM, Higgs G. Reasons for tooth extraction in four general dental practices in South Wales. Br Dent J. 2005; 198(5):275-278

3. Chestnutt IG, Binnie VI, Taylor MM. Reasons for tooth extraction in Scotland. J Dent. 2000;28(4):295-297.

4. Reich E, Hiller KA. Reasons for tooth extraction in the western states of Germany. Community Dent Oral Epidemiol. 1993;21(6):379-383.

5. Haugejorden O, Klock KS. The relative importance of reasons for tooth extraction in terms of potential tooth years of life lost (PYLL). Community Dent Health. 1992;9(4):369-379.

6. Corbet EF, Davies WI. Reasons given for tooth extraction in Hong Kong. Community Dent Health. 1991;8(2):121-130.

7. Szabo J, Szabo I, Kiralyfalvi L. Survey of reasons for tooth extraction in the framework of government-sponsored dentistry. Fogorv $\mathrm{Sz}$. 1991;84(6-7):161-166. Hungarian.

8. Stephens RG, Kogon SL, Jarvis AM. A study of the reasons for tooth extraction in a Canadian population sample. $J$ Can Dent Assoc. 1991;57(6):501-504. 
9. Mosha HJ, Lema PA. Reasons for tooth extraction among Tanzanians. East Afr Med J. 1991;68(1):10-14.

10. Kay EJ, Blinkhorn AS. The reasons for the extraction of various tooth types in Scotland. J Dent. 1987;15(1):30-33.

11. Mieler I, Vahnauer D. Statistical analysis of reasons for tooth extraction with special reference to periodontal diseases. Dtsch Stomatol. 1970;20(1):42-52. German.

12. Al Shammari KF, Al Ansari JM, Al Melh MA, Al Khabbaz AK. Reasons for tooth extraction in Kuwait. Med Princ Pract. 2006;15(6): $417-422$.

13. Morita M, Kimura T, Kanegae M, Ishikawa A, Watanabe T. Reasons for extraction of permanent teeth in Japan. Community Dent Oral Epidemiol. 1994;22(5 Pt 1):303-306.

14. Ong G, Yeo JF, Bhole S. A survey of reasons for extraction of permanent teeth in Singapore. Community Dent Oral Epidemiol. 1996;24(2): 124-127.

15. Da'ameh D. Reasons for permanent tooth extraction in the North of Afghanistan. J Dent. 2006;34(1):48-51.

16. Quteish Taani DS. Periodontal reasons for tooth extraction in an adult population in Jordan. J Oral Rehabil. 2003;30(1):110-112.

17. Hamasha AA, Al Qudah MA, Bataineh AB, Safadi RA. Reasons for third molar teeth extraction in Jordanian adults. J Contemp Dent Pract. 2006;7(5):88-95.
18. McCaul LK, Jenkins WM, Kay EJ. The reasons for extraction of permanent teeth in Scotland: a 15-year follow-up study. $\mathrm{Br}$ Dent $J$. 2001;190(12):658-662.

19. Farsi J. Common causes of extraction of teeth in Saudi Arabia. Saudi Dental J. 1992;4(3):101-105.

20. Spalj S, Plancak D, Juric H, Pavelic B, Bosnjak A. Reasons for extraction of permanent teeth in urban and rural populations of Croatia. Coll Antropol. 2004;28(2):833-839.

21. Haddad I, Haddadin K, Jebrin S, Ma'ani M, Yassin O. Reasons for extraction of permanent teeth in Jordan. Int Dent J. 1999;49(6):343-346.

22. Angelillo IF, Nobile CG, Pavia M. Survey of reasons for extraction of permanent teeth in Italy. Community Dent Oral Epidemiol. 1996; 24(5):336-340.

23. Central Department of Statistics and Information. Statistical Yearbook. Saudi Arabia, 2010. Available from: http://www.cdsi.gov.sa/yb46/ Pages/MixFPage.htm. Accessed July 10, 2013.

24. Lesolang RR, Motloba DP, Lalloo R. Patterns and reasons for tooth extraction at the Winterveldt Clinic: 1998-2002. SADJ. 2009;64(5): 214-215.

25. Wahab F. A survey of reasons for extraction of permanent teeth in Jordan. Saudi Dental Journal. 2001;13(3):148-154.
Clinical, Cosmetic and Investigational Dentistry

\section{Publish your work in this journal}

Clinical, Cosmetic and Investigational Dermatology is an international, peer-reviewed, open access, online journal that focuses on the latest clinical and experimental research in all aspects of skin disease and cosmetic interventions. All areas of dermatology will be covered; contributions will be welcomed from all clinicians and

\section{Dovepress}

basic science researchers globally. This journal is indexed on CAS The manuscript management system is completely online and includes a very quick and fair peer-review system, which is all easy to use. Visit http://www.dovepress.com/testimonials.php to read real quotes from published authors. 